\title{
Integrated probe for electrochemical analysis of small volume droplets
}

Ning Dang, Nader Djelidi, Gustavo Adrián Echeveste Salazar, Alain Walcarius, Liang Liu*, Mathieu Etienne*

Université de Lorraine, CNRS, Laboratoire de Chimie Physique et Microbiologie pour les Matériaux et l'Environnement (LCPME), F-54000 Nancy, France

*Email: mathieu.etienne@univ-lorraine.fr; liang.liu@univ-lorraine.fr

\begin{abstract}
Analysis of small volume droplets is increasingly important in biology, environment, and material science. In this work, an integrated probe consisting of a Pt microelectrode wrapped with an $\mathrm{Ag} / \mathrm{AgCl}$ wire and inserted into an outer capillary filled with $\mathrm{KCl}$ is developed as sensor for electrochemical analysis of small volume droplets $(20 \mu \mathrm{L})$. With a 3D-printed holder, the design allows easy fabrication, dismantling and re-assembly, which is important for renewing the probe. The integrated probe shows acceptable ohmic drop with electrochemical impedance spectroscopy, thus offers reliable and reproducible potentiometric and voltammetric measurements in bulk solutions. The ring-shaped opening between the inner microelectrode and the outer capillary also enables homogenous current distribution when applying potential between $\mathrm{Pt}$ and $\mathrm{Ag} / \mathrm{AgCl}$. Based on this, two droplet systems mimicking atmospheric corrosion are in-situ studied: (1) $\mathrm{Fe}^{3+}$ droplet on bare and silane-coated steel; (2) $\mathrm{Cu}^{2+}$ in a $\mathrm{H}_{2} \mathrm{SO}_{4}$ droplet
\end{abstract}


on copper. The concentration of $\mathrm{Fe}^{3+} / \mathrm{Fe}^{2+}$ and $\mathrm{Cu}^{2+}$ in the droplet is monitored with time, allowing interfacial corrosion reactions between the droplet and the substrate to be studied.

Keywords: Microelectrode; Droplet analysis; Potentiometry; Anodic stripping voltammetry; Atmospheric corrosion.

\section{Introduction}

Droplets of small volume are very common in nature, such as saliva on the tongue [1-4], sweat on the skin[5-7], as well as rain drops on solid supports like leaves[8] or metals [9-11]. Besides, artificial occasions, such as highly humid chamber [12,13] and ink-jet printing [14], may also generate small droplets on sample surfaces. Thus, the chemical analysis of small droplets is highly desired. One strategy is to transfer the sample for spectrometric or electrochemical analysis, typically through microfluidic devices [15-18] and screen-printed electrodes [19-22]. These sensors can be highly sensitive and are well developed and commercialized. However, they consume the sample and therefore can only provide static chemical information of the droplet. For tracking the evolution of chemistry in the droplet, miniaturized sensors that can insitu analyse small volume samples are required. This may allow studying the interfacial chemistry between the droplet and the support surfaces.

As a direct bridge between chemistry and instrument measurable electrical signals, electrochemical analysis is naturally ideal for constructing in-situ miniaturized sensors. This is usually achieved by microelectrodes due to the high spatial and temporal resolution [23-26]. The fabrication of microelectrodes is matured and widely applied for scanning electrochemical microscopy. Nevertheless, for electroanalysis in a small droplet, it is essential to have at least 
another reference electrode. The technical challenge is to combine the microelectrode with the micro-reference electrode and have both in contact with the same droplet. A promising approach is to use theta-capillary. Souto et al. developed dual microelectrode probes that consist of a $\mathrm{Mg}^{2+}$ ion-selective electrode and a reference electrode for monitoring the concentration evolution of $\mathrm{Mg}^{2+}$ in the close vicinity of $\mathrm{Mg}$ substrate [27]. Unwin et al. developed scanning electrochemical cell microscopy for carrying out local electrochemical measurements revolutionarily in a nanometer-sized meniscus that spreads on a sample surface $[28,29]$. Due to the presence of two electrodes (one serves as reference electrode) in the probe, it allows approaching the probe and detecting the droplet/sample contact even for insulating samples [30]. The system has been used for studying various interfacial reactions between samples and droplets, including electrocatalysis [31-42], charge-discharge in batteries [43-46], and corrosion [47-49], etc. However, these theta-capillary based working-reference dual electrodes face a technical challenge of regeneration. They cannot be polished like classical single microelectrodes as the polishing paste or the debris may block the opening of the reference capillary.

Herein, we develop a new integrated probe for in-situ quantitative electrochemical analysis of small volume droplets on solid surfaces regardless of the nature of droplet and support. It allows monitoring the interfacial reactions between the droplet and the support with relatively high spatial resolution. A Pt microelectrode is wrapped with $\mathrm{Ag} / \mathrm{AgCl}$ wire on its shield and is inserted into an external capillary filled with $\mathrm{KCl}$ electrolyte. The special design allows easy fabrication, dismantling and re-assembly, so that the probe can be completely regenerated by polishing the working electrode and replacing the electrolyte in the outer capillary. Moreover, the reference 
electrode has a ring-shaped opening around the working electrode, providing an acceptable resistance and homogeneous current distribution for potentiometric and amperometric measurements. The integrated probe is characterized and calibrated in bulk solutions of large volume, and then is approached to $20 \mu \mathrm{L}$ droplets for electrochemical analysis. It is proved to be useful in in-situ and spatially-resolved corrosion analysis [50]. Besides, more possibilities in biological analysis and environmental monitoring should also be seen in the future by sensing small droplets.

\section{Experimental}

\subsection{Chemical and materials}

The metal wires (Pt of $25 \mu \mathrm{m}$ and $1 \mathrm{~mm}$ diameter, $\mathrm{Ag}$ of $50 \mu \mathrm{m}$ diameter) and the Pt foil are purchased from ChemPUR, Germany. The inner glass capillary for sealing Pt microelectrode is purchased from Sutter Instrument $(B F 150-75-10$, inter diameter $=0.75 \mathrm{~mm}$, outer diameter $=$ $1.5 \mathrm{~mm})$. The outer glass capillary is customized by Hilgenberg GMBH with inter diameter $=$ $1.8 \mathrm{~mm}$, outer diameter $=2.4 \mathrm{~mm}$. Metal plates of $\mathrm{Fe}(99.99 \%$, ChemPUR) and $\mathrm{Cu}(99.9 \%)$, as well as microscope glass slides, are used as samples for droplet analysis. The metal plates are polished with $\mathrm{SiC}$ paper up to 4000 grit and then cleaned by sonication in ethanol and acetone. For comparison, one Fe plate is coated with silane by electrodeposition. The deposition solution consists of 3.3 vol. \% methyltriethoxysilane (98 \%, Sigma), 1.15 vol. \% tetraethoxysilane ( $98 \%$, Sigma), 2/1 (v/v) ethanol/water mixed solvent and $0.2 \mathrm{M} \mathrm{NaNO}_{3}$, with $\mathrm{pH}$ adjusted to 4 using $\mathrm{HCl}$. The solution is pre-hydrolyzed at $35^{\circ} \mathrm{C}$ for $48 \mathrm{~h}$. The electrodeposition is carried out on Fe plate at $-1.4 \mathrm{~V}(v s . \mathrm{Ag} / \mathrm{AgCl})$ for $300 \mathrm{~s}$, and the film is rinsed by water and dried before use 
[51-53]. All the chemicals used in this work are reagent grade and used without further purification.

\subsection{Preparation of the integrated probe}

The integrated probe consists of three parts: a Pt micro-disk electrode, an $\mathrm{Ag} / \mathrm{AgCl}$ wire, and an outer capillary filled with electrolyte, as illustrated in Fig. 1A. The Pt micro-disk electrode is prepared with the same way as for scanning electrochemical microscopy measurements. A $25 \mu \mathrm{m}$ diameter Pt wire is sealed into a pulled glass capillary by epoxy resin. The outer diameter of the original capillary is $1.5 \mathrm{~mm}$, and after pulling it has an outer diameter of $c a .50 \mu \mathrm{m}$ at the tip, which is about two times as that of the $\mathrm{Pt}$ wire. The $\mathrm{Ag} / \mathrm{AgCl}$ wire is prepared by oxidizing a $50 \mu \mathrm{m}$ diameter $\mathrm{Ag}$ wire in $0.1 \mathrm{M} \mathrm{KCl}$ solution at $0.12 \mathrm{~V}$ ( $v \mathrm{~s} . \mathrm{Ag} / \mathrm{AgCl}$ ) for $30 \mathrm{~s}$. After rinsing with deionized water, the wire is wrapped around the glass shield of Pt microelectrode and fixed with tacky glue. The outer capillary with $1.8 \mathrm{~mm}$ inner diameter is pulled to have a short tip of ca. $1 \mathrm{~cm}$. It is then polished to have desired inner diameter of opening. The Pt micro-disk electrode stick with $\mathrm{Ag} / \mathrm{AgCl}$ wire is inserted into the outer capillary and fixed together with screw in a $3 \mathrm{D}$ printed holder that allows fixing to a motor for positioning the probe. The last step is to soak electrolyte into the integrated probe through the thin gap at the tip between the inner electrode and the outer capillary to obtain a real reference electrode. For easily dismantling the outer capillary and refreshing the surface of inner microelectrode, $0.1 \mathrm{M} \mathrm{KCl}$ aqueous solution is filled as electrolyte rather than agar gel that is sometimes used [54]. The photographs of fabrication of the integrated probe are shown in Fig. 1B. We recommend using $\mathrm{Cu}$ wire with insulating coating to make the electrical contact for both the Pt microelectrode 
and the $\mathrm{Ag} / \mathrm{AgCl}$ wire to avoid short contact between them.

(A)

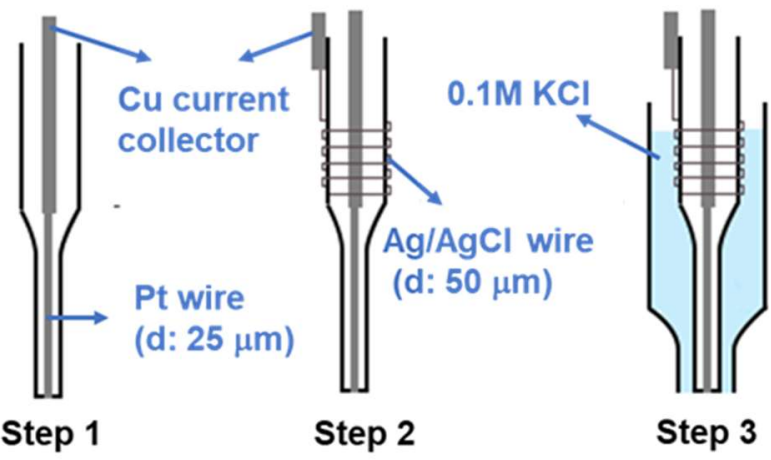

Step 1: Preparation of Pt microelectrode $\left(R_{\mathrm{g}} \approx 2\right)$

Step 2: Preparation of internal probe

(B)

Step 3: Assembling of integrated probe
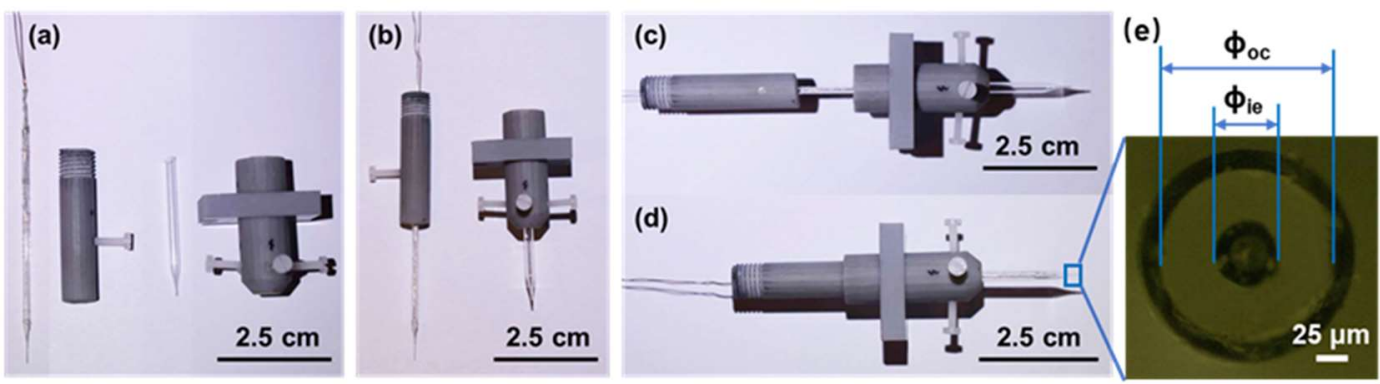

Fig. 1. (A) Scheme of the fabrication of integrated probe. (B) (a-d) Photographs illustrating

different steps of the fabrication, (e) tip of the integrated probe, gap width (W) = inner

diameter of outer capillary $\left(\varphi_{\mathrm{oc}}\right)-$ outer diameter of inner electrode $\left(\phi_{\mathrm{ie}}\right)$.

A major technical advantage of this design is the ease of fabrication and refreshing of the probe.

All the three parts, namely the Pt micro-disk electrode, the $\mathrm{Ag} / \mathrm{AgCl}$ reference electrode and the outer glass capillary, do not have strict dimension requirement. They can be easily dismantled and remounted. After dismantling the probe by removing the outer capillary, the inner microelectrode can be polished on a home-made polisher [55], as shown in the Video. It is mounted on the polisher, with both the polishing plate and the electrode rotating. The microelectrode is approached to gently touch a $0.3 \mu \mathrm{m}$ diamond lapping film attached on the polishing plate. During polishing, the probe surface is rinsed by water. Generally, a few seconds 
is enough for refreshing the probe. Afterwards, the outer capillary is mounted again and the electrolyte is refilled. If necessary, the $\mathrm{Ag} / \mathrm{AgCl}$ wire can also be regenerated by re-oxidation of Ag. This means that the integrated probe can be easily and completely refreshed, which is highly important for practical applications in electrochemical analysis. Moreover, the $\mathrm{Ag} / \mathrm{AgCl}$ wire has much higher area than the Pt microelectrode, so it can also serve as counter electrode in a two-electrode system for amperometric measurements. The ring-shaped gap between the inner microelectrode and the outer capillary allows uniform symmetrical current distribution. Like classical reference electrodes, the integrated probe can be stored by immersion in the $\mathrm{KCl}$ solution when not in use.

\subsection{Characterization of the integrated probe}

The integrated probe is characterized by electrochemical impedance spectroscopy (EIS), potentiometry and cyclic voltammetry $(\mathrm{CV})$ in bulk electrolyte solutions of large volume ( $c$ a. $20 \mathrm{~mL}$ ). EIS is performed in $0.1 \mathrm{M} \mathrm{KCl}$ solution for measuring the resistance of the reference electrode of the integrated probe. $\mathrm{The} \mathrm{Ag} / \mathrm{AgCl}$ wire of the integrated probe is connected as working electrode (WE), a commercial $\mathrm{Ag} / \mathrm{AgCl}$ electrode is used as reference electrode (RE) and a Pt foil is used as counter electrode (CE). The measurement is carried out at open circuit potential (OCP) with a $10 \mathrm{mV}$ sinusoidal perturbation in the frequency range of $100 \mathrm{kHz}$ to 0.1 $\mathrm{Hz}$ on an Autolab potentiostat (PGSTAT 302N, Metrohm).

The potentiometry of the integrated probe is carried out in $\mathrm{Fe}^{3+} / \mathrm{Fe}^{2+}$ and $\left[\mathrm{Fe}(\mathrm{CN})_{6}\right]^{3-} /\left[\mathrm{Fe}(\mathrm{CN})_{6}\right]^{4-}$ redox couple solutions. The $\mathrm{Fe}^{3+} / \mathrm{Fe}^{2+}$ solutions are prepared by dissolving $\mathrm{Fe}_{2}\left(\mathrm{SO}_{4}\right)_{3}$ and $\mathrm{FeSO}_{4}$ in $0.1 \mathrm{M} \mathrm{KCl}$ electrolyte with the ratio of $50: 1,10: 1,1: 1,1: 10,1: 50$ (in $\mathrm{mM}$ ). In order to inhibit 
the hydrolysis of the $\mathrm{Fe}^{3+} / \mathrm{Fe}^{2+}$, $\mathrm{pH}$ of the solutions was adjusted to $c a$. 1.5 with $\mathrm{H}_{2} \mathrm{SO}_{4}$. The $\left[\mathrm{Fe}(\mathrm{CN})_{6}\right]^{3-} /\left[\mathrm{Fe}(\mathrm{CN})_{6}\right]^{4-}$ solutions are prepared by dissolving $\mathrm{K}_{3} \mathrm{Fe}(\mathrm{CN})_{6}$ and $\mathrm{K}_{4} \mathrm{Fe}(\mathrm{CN})_{6}$ in $0.1 \mathrm{M} \mathrm{KCl}$ electrolyte with the ratio of $1: 0.1,0.164: 0.1,0.1: 0.1,0.1: 0.164,0.1: 1$ (in $\mathrm{mM}$ ). The OCP between the Pt microelectrode and the $\mathrm{Ag} / \mathrm{AgCl}$ reference electrode of the integrated probe is recorded by a voltammeter with high input resistance (Keithley 6430). In order to examine the response time of the integrated probe, the OCP was also record in $\mathrm{Fe}^{3+} / \mathrm{Fe}^{2+}$ solutions while changing the concentration ratio by adding drops of $\mathrm{Fe}^{3+}$ or $\mathrm{Fe}^{2+}$ every $600 \mathrm{~s}$. The solution was kept under stirring for rapid and homogeneous mixture of the species.

The CV of the integrated probe is measured in a solution with $1 \mathrm{mM}$ ferrocenedimethanol $(\mathrm{FcMeOH})$ and $0.1 \mathrm{M} \mathrm{KCl}$. The Pt microelectrode of the integrated probe is connected as WE. For two-electrode system that involves only the integrated probe, the $\mathrm{Ag} / \mathrm{AgCl}$ wire is connected as both $\mathrm{RE}$ and $\mathrm{CE}$. A three-electrode system that connects the $\mathrm{Ag} / \mathrm{AgCl}$ wire of the integrated probe as $\mathrm{RE}$ and a separate $\mathrm{Pt}$ wire $(1 \mathrm{~mm}$ diameter $)$ as $\mathrm{CE}$ is also measured for comparison. The potential is scanned in the range of 0 to $0.6 \mathrm{~V}$ at $10 \mathrm{mV} / \mathrm{s}$ scan rate.

\subsection{Electrochemical analysis in droplets}

Fig. 2 illustrates the setup of droplet analysis using the integrated probe. A major concern is to keep the humidity of the environment to minimize the evaporation of the droplet. The sample is placed in a $3 \mathrm{D}$ printed plastic chamber with water reservoir. The hole at the top of the chamber allows putting the droplet by micropipette and inserting the integrated probe. Afterwards, the gap between the probe and the chamber is rapidly sealed with parafilm, and then the probe is approached to be in contact with the droplet. 
$20 \mu \mathrm{L}$ droplets of $\mathrm{Fe}\left(\mathrm{NO}_{3}\right)_{3}$ in concentration of 1, 5, 10, 25, $50 \mathrm{mM}$ are dropped on bare and silane-treated Fe plates for potentiometric measurements. The measurement configuration is the same as potentiometric characterization of the probe in bulk solution. For amperometric measurements, $20 \mu \mathrm{L}$ droplets of $0.1 \mathrm{M} \mathrm{H}_{2} \mathrm{SO}_{4}$ are dropped on $\mathrm{Cu}$ plates, and concentration of $\mathrm{Cu}^{2+}$ is traced by anodic stripping using the integrated probe. The $\mathrm{Pt}$ microelectrode is connected as WE, and the $\mathrm{Ag} / \mathrm{AgCl}$ wire is connected as $\mathrm{RE}$ and $\mathrm{CE}$ for a two-electrode system. The stripping is carried out by preconcentration of $\mathrm{Cu}$ at $-0.2 \mathrm{~V}$ for $30 \mathrm{~s}$ followed by $\mathrm{CV}$ scans from -0.08 to $0.6 \mathrm{~V}$ at scan rate of $50 \mathrm{mV} / \mathrm{s}$. The calibration of $\mathrm{Cu}$ stripping was achieved by the integrated probe in $0.1 \mathrm{M} \mathrm{H}_{2} \mathrm{SO}_{4}$ and $\mathrm{CuSO}_{4}$ solutions with $\mathrm{Cu}^{2+}$ concentration of $1,2.5,5$, $10,50 \mathrm{mM}$. For both potentiometric and amperometric measurements, control experiments are carried out on glass slides with the same protocols.

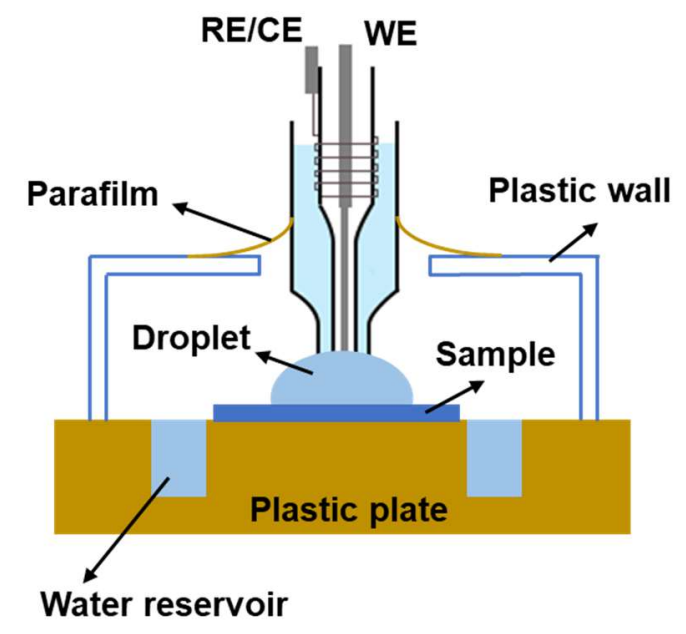

Fig. 2. Scheme of the setup for electrochemical droplet analysis using integrated probe.

\section{Results and Discussion}

In the integrated probe, the inner $\mathrm{Pt}$ microelectrode serves as $\mathrm{WE}$, and the $\mathrm{Ag} / \mathrm{AgCl}$ wire with $\mathrm{KCl}$ electrolyte serves as RE. Therefore, it is essential to evaluate the stability and reliability of 
the configuration especially for the $\mathrm{Ag} / \mathrm{AgCl} \mathrm{RE}$. This is first carried out in bulk solutions by measuring their electrochemical behavior. Three aspects are tested: the ohmic resistance in the gap between the inner microelectrode and the outer capillary, the potentiometric and voltammetric measurements in standard redox solutions. As a further step, the probes are used for droplet analysis. Potentiometric analysis is carried out by following the open circuit potential of a $\mathrm{Fe}^{3+}$ droplet on Fe plate, and amperometric analysis of $\mathrm{Cu}^{2+}$ by anodic stripping is measured in a $\mathrm{H}_{2} \mathrm{SO}_{4}$ droplet on $\mathrm{Cu}$ plate. The results allow analyzing the evolution of metal ion concentration, which reflect the corrosion reactions between the droplet and the metals.

\subsection{Evaluation of the integrated probe in bulk solutions}

A major criterion for $\mathrm{RE}$ is the ohmic resistance that originates from the ion exchange between its internal electrolyte and the external measurement media, as it determines the ohmic drop in electrochemical measurements [56]. In the integrated probe, it is mainly affected by the gap between the inner microelectrode and the outer capillary, which should allow ion exchange yet have low rate of leakage. Here, the ohmic resistance is measured by EIS in a three-electrode system, with the $\mathrm{Ag} / \mathrm{AgCl}$ wire of the integrated probe as $\mathrm{WE}$, a commercial $\mathrm{Ag} / \mathrm{AgCl}$ reference electrode as RE and a Pt foil as CE as illustrated in Fig. 3A [57,58]. In this case, the DC resistance at high frequency mainly reflects the ion transfer resistance of the gap. From the Nyquist diagram (Fig. 3B), it is seen that the interceptions of the curves with the real axis tested with outer capillaries ( $c a . \geq 46 \mathrm{k} \Omega$ ) are orders of magnitude higher than that measured without the outer capillary ( $c a .40 \Omega$ ). In addition, the DC resistance increases with decreasing the gap width $W$ between inner electrodes and outer capillaries. This confirms that the DC resistance 
mainly reflects the ion exchange through the gap. The dramatic increase in the DC resistance to hundreds of $\mathrm{k} \Omega$ might also introduce artifacts for high frequency measurements, which could be the reason for the striking distortion of the spectra.
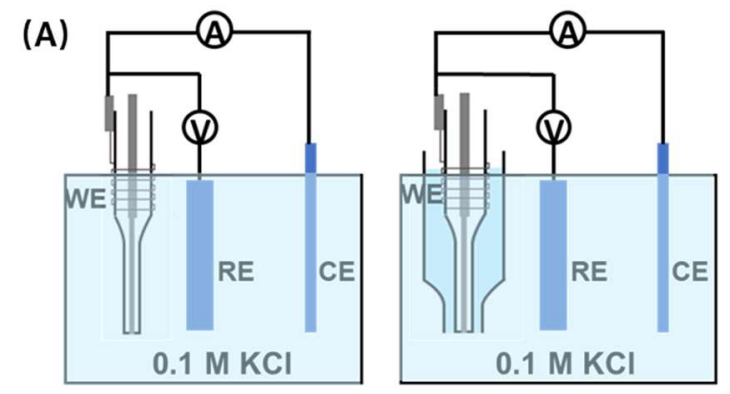

(B)

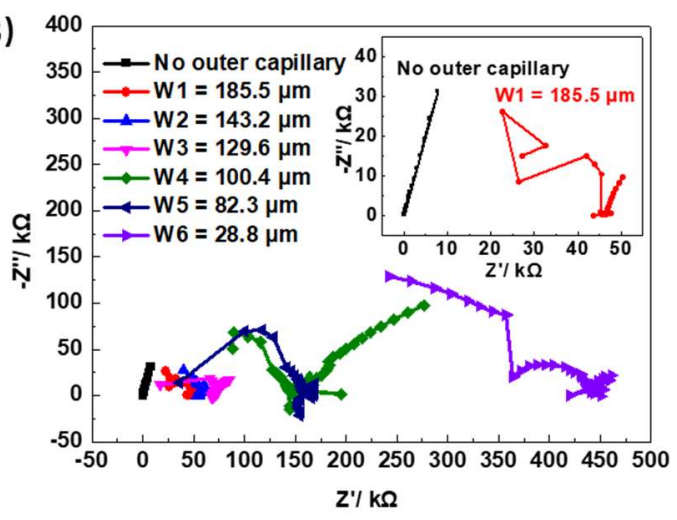

(C)

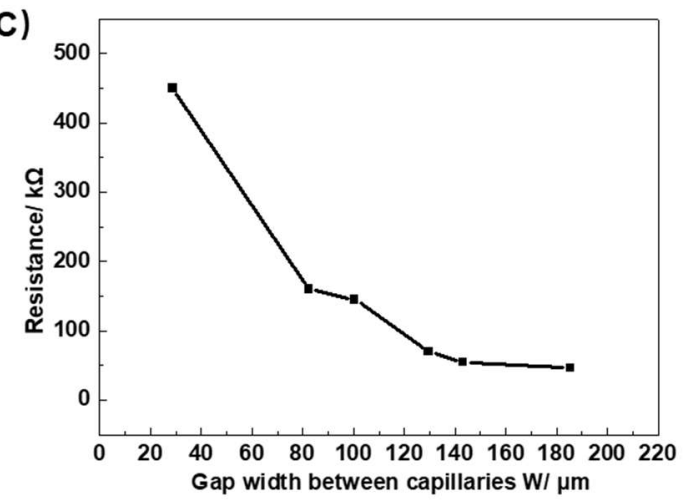

Fig. 3. (A) Scheme of EIS measurement; (B) Nyquist plots of $\mathrm{Ag} / \mathrm{AgCl}$ wire of the integrated probe in $0.1 \mathrm{M} \mathrm{KCl}$ solution with different gap width (W) between inner electrodes and outer capillaries; (C) Ion transfer resistance of integrated probes with different gap width.

Considering that the WE has a diameter of $25 \mu \mathrm{m}$, the double layer capacitance is about $98 \mathrm{pF}$ (in $0.1 \mathrm{M} \mathrm{KCl}$ solution [59]), and the current in typical CV or amperometric measurements usually does not exceed $10 \mathrm{nA}$. Based on the measured resistance value, one may estimate that the ohmic drop of the system is in the range of $1-4 \mathrm{mV}$, and the time constant is around $40 \mu \mathrm{s}$. This is acceptable for most of the electrochemical measurements. Besides, when the gap width is in the range of $c a .129$ to $185 \mu \mathrm{m}$, the DC resistance has very similar values (Fig. 3C), indicating that the cell properties are not sensitive to the gap width in this range. This leaves 
flexibility for polishing the outer capillaries, and EIS measurement may serve as a tool for quality control of the integrated probe. Generally, we recommend to have a gap width around $130 \mu \mathrm{m}$, as smaller gap would yield a significant increase in the DC resistance, while larger gap might increase the risk of solution leakage.

The potentiometric analysis of the integrated probe is carried out in redox couple solutions by measuring the open circuit potential between the inner Pt microelectrode and the $\mathrm{Ag} / \mathrm{AgCl}$ wire in the outer capillary, as illustrated in Fig. 4A. The probe is initially placed in air, and then it is approached to immerse in the redox solution when the potential is monitored. Fig. 4B shows the potential of the probe measured in $\mathrm{Fe}^{3+} / \mathrm{Fe}^{2+}$ redox couple solutions with different ratio. The small plateau in the first $20 \mathrm{~s}$ corresponds to the "free" potential of the probe in air, which is meaningless. When the probe is in contact with the solution, the potential changes quickly before reaching equilibrium. The response time of the probe when initially approaching from air to solution is $c a$. 50-150 s depending on the solution. However, the response is faster for the variation of concentration when the probe is already immersed in the solution, as shown in Fig. 4D. The response time is reduced to $c a .30 \mathrm{~s}$, which is much longer than the $\mathrm{RC}$ time constant of WE. This might be attributed to the slow ion exchange in the narrow gap between inner and outer capillaries. Similar phenomenon can also be seen in ion-selective electrodes where membranes with limited ionic conductivity are used. However, once the equilibrium is reached, the potential is highly stable for a long time of measurement. The potential versus the $\mathrm{Fe}^{3+} / \mathrm{Fe}^{2+}$ ratio can be well fitted to Nernst equation as shown in Fig. 4C. The slope is $c a .59 \mathrm{mV}$, and the $R^{2}$ is 0.996 . The potential also accurately reflects the dynamic change of redox ratio in Fig. 4D. Similar trends are also seen with $\mathrm{Fe}(\mathrm{CN})_{6}{ }^{3-} / \mathrm{Fe}(\mathrm{CN})_{6}{ }^{4-}$ redox probes (Fig. S1), and the results 
confirm that the integrated probe is reliable for potentiometric analysis in redox solutions.

(A)

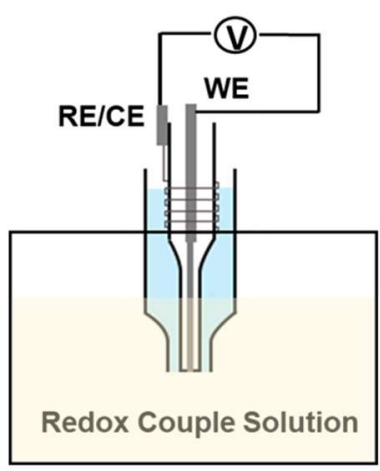

(C)

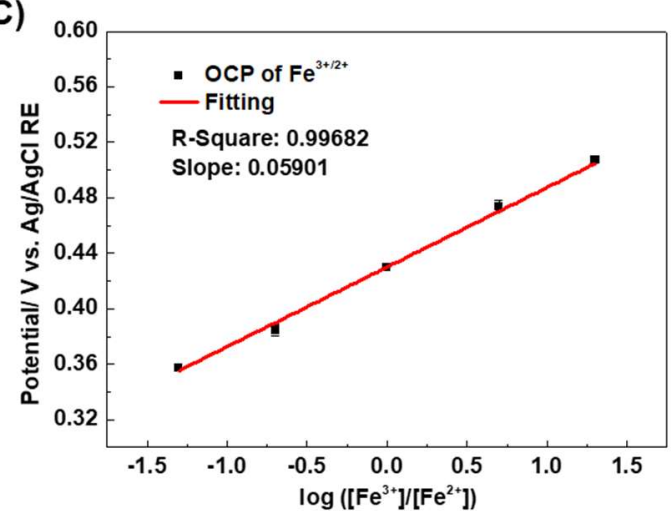

(B)

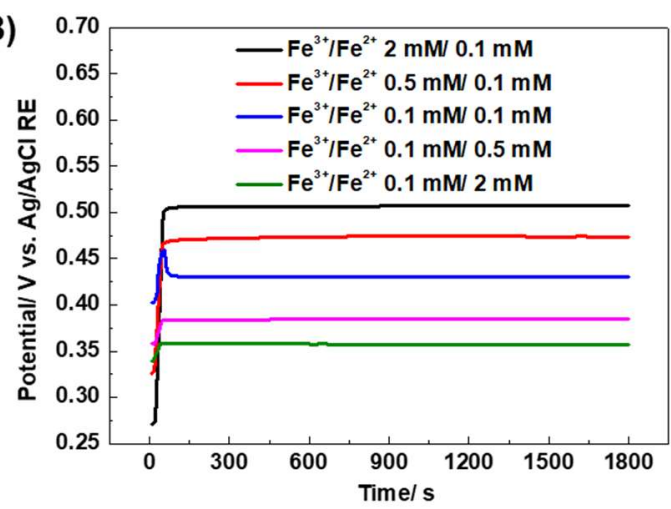

(D)

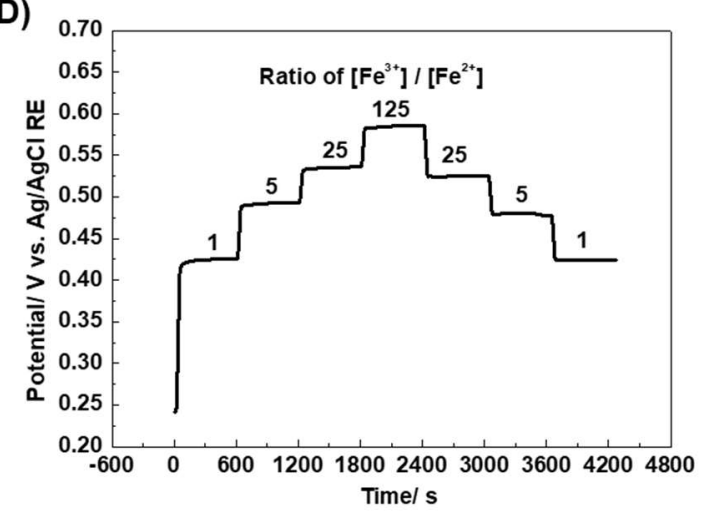

Fig. 4. (A) Scheme of potentiometric measurements of the integrated probe in bulk solutions;

(B) Potential variation in $\mathrm{Fe}^{3+} / \mathrm{Fe}^{2+}$ redox solutions with different concentration ratio; (C)

Potential versus $\log \left(\left[\mathrm{Fe}^{3+}\right] /\left[\mathrm{Fe}^{2+}\right]\right)$; (D) Potential steps following the variation of $\left[\mathrm{Fe}^{3+}\right] /\left[\mathrm{Fe}^{2+}\right]$ ratio in the solution.

Besides potentiometry, the integrated probe is also used for voltammetric measurements.

Different configurations are compared for the measurement and illustrated in Fig. 5A: (a) Pt microelectrode as $\mathrm{WE}, \mathrm{Ag} / \mathrm{AgCl}$ wire as quasi-reference electrode (QRE) without outer capillary, and a Pt wire of $1 \mathrm{~mm}$ diameter as $\mathrm{CE}$; (b) $\mathrm{Pt}$ microelectrode as $\mathrm{WE}, \mathrm{Ag} / \mathrm{AgCl}$ wire with $0.1 \mathrm{M} \mathrm{KCl}$ in the outer capillary as RE, and a Pt wire of $1 \mathrm{~mm}$ diameter as CE; (c) Pt microelectrode as WE, and $\mathrm{Ag} / \mathrm{AgCl}$ wire in $0.1 \mathrm{M} \mathrm{KCl}$ in the outer capillary connected as both 
RE and CE. The results show classical sigmoidal shape voltammogram of microelectrodes in 1 $\mathrm{mM} \mathrm{FcMeOH}$ solution, and there is no significant difference between the three configurations (Fig. 5B). Moreover, the measurements are highly reproducible for multiple experiments with configuration (c) as shown in Supplementary Information (Fig. S2). This suggests that the $\mathrm{Ag} / \mathrm{AgCl}$ wire in $0.1 \mathrm{M} \mathrm{KCl}$ in the outer capillary functions well as $\mathrm{RE}$, and it can even be used as $\mathrm{CE}$ as the area of $\mathrm{Ag} / \mathrm{AgCl}$ is much higher than that of $\mathrm{Pt}$ microelectrode so that the polarization is negligible. The resistance of the gap between Pt microelectrode and the outer capillary appears to have no significant influence on the results, which is due to the low current in the measurement. This suggests that the integrated probe can also be used for voltammetric analysis in a two-electrode system, with the Pt microelectrode as $\mathrm{WE}$ and the $\mathrm{Ag} / \mathrm{AgCl}$ wire in $0.1 \mathrm{M} \mathrm{KCl}$ in the outer capillary as RE and CE.

(A)
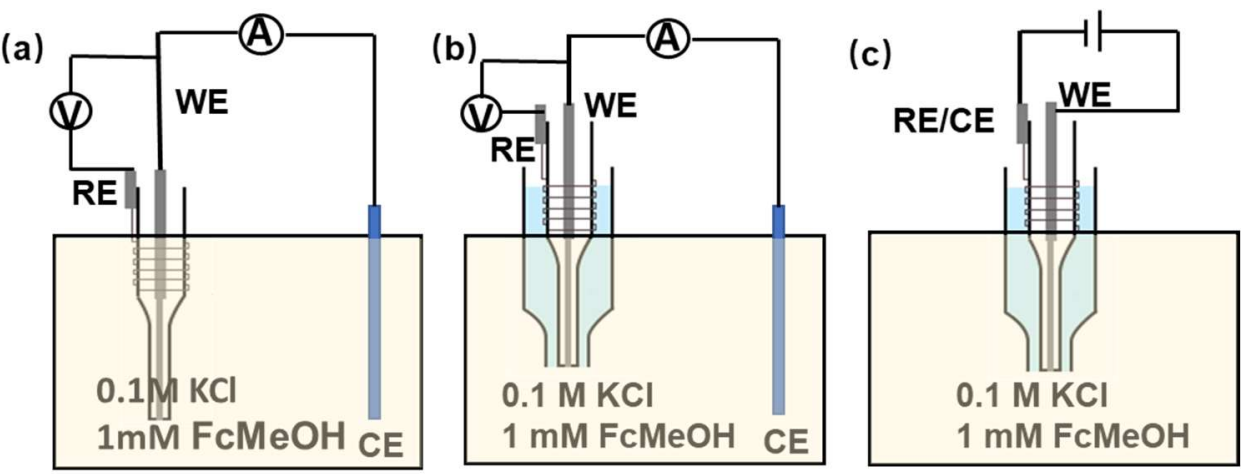

(B)

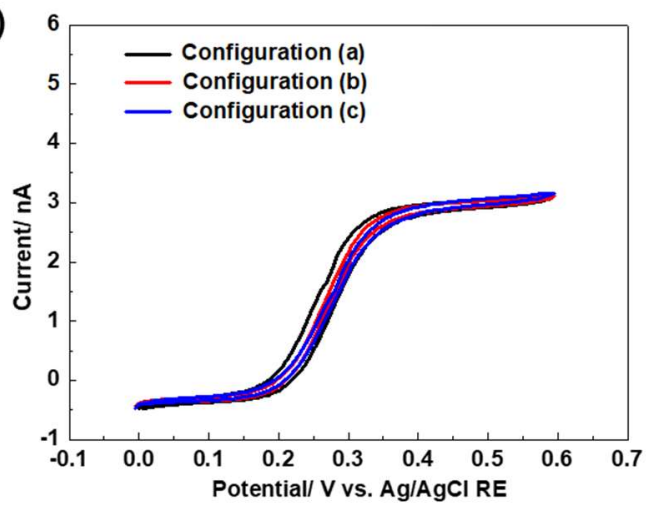

Fig. 5. (A) Schemes of CV in $1 \mathrm{mM}$ FcMeOH solution by integrated probe; (B) $\mathrm{CV}$ of the 
integrated probe in $1 \mathrm{mM} \mathrm{FcMeOH}$ solution with different configurations. Scan rate in $\mathrm{CV}$ measurement is $10 \mathrm{mV} / \mathrm{s}$.

The results above show that the integrated probe has acceptable ohmic resistance for the gap between the Pt microelectrode and the outer capillary. This allows the probe to be reliably used for potentiometric and voltammetric measurements in bulk solutions with large volume.

\subsection{Potentiometric measurements of $\mathrm{Fe}^{3+}$ droplets on Fe plate}

As designed, the small size of the tip of the integrated probe allows electrochemical measurements in small droplets. This is especially useful for tracking the evolution of chemistry of droplets, which may further indirectly reveal the kinetics of reactions at the droplet/substrate interface. For example, Turyan et al. analyzed the oxidation kinetics of therapeutic proteins in $150 \mu \mathrm{L}$ droplets by potentiometry for rapid screening of their activities [60]. A classical qualitative method for evaluating the corrosion activity of metals is by droplets that change color upon reaction with the metal, e.g. $\mathrm{CuSO}_{4}$. Here, we demonstrate an example of potentiometric analysis using the integrated probe for tracking the reduction of $\mathrm{Fe}^{3+}$ in a $20 \mu \mathrm{L}$ droplet by steel substrate. The main reactions are as follows:

$\mathrm{Fe}^{3+}+e \leftrightharpoons \mathrm{Fe}^{2+}$

$F e^{2+}+2 e \leftrightharpoons F e_{\text {surf }}$

Besides, in aerated droplets, the reduction of $\mathrm{O}_{2}$ and $\mathrm{H}^{+}$may also drive the corrosion of $\mathrm{Fe}$ :

$\mathrm{O}_{2}+2 \mathrm{H}_{2} \mathrm{O}+4 e \rightarrow 4 \mathrm{OH}^{-}$

$2 H^{+}+2 e \rightarrow H_{2}$ 
Considering the limited concentration of dissolved $\mathrm{O}_{2}$ and the acidity of solution, R1 and R2 are expected to be dominant in the system. Thus, the concentration ratio between $\mathrm{Fe}^{3+}$ and $\mathrm{Fe}^{2+}$ in the droplet follows Nernst Equation, which can be measured by the potential of the integrated probe:

$E_{\text {probe }}=E_{F e^{3+} / F e^{2+}}^{0 \prime}-\frac{R T}{F} \ln \frac{\left[F e^{2+}\right]}{\left[F e^{3+}\right]} \quad(E q .1)$

where $E_{\mathrm{Fe}^{3+} / \mathrm{Fe}^{2+}}^{0 \prime}$ refers to the formal potential of $\mathrm{Fe}^{3+} / \mathrm{Fe}^{2+}$ redox couple, $R$ is the ideal gas constant $\left(8.314 \mathrm{~J} \cdot \mathrm{K}^{-1} \cdot \mathrm{mol}^{-1}\right), T$ is the temperature $(298 \mathrm{~K})$ and $F$ is the Faradic constant $(96,485$ $\left.\mathrm{C} \cdot \mathrm{mol}^{-1}\right)$. By measuring the potential of the probe in $1: 1 \mathrm{Fe}^{3+} / \mathrm{Fe}^{2+}$ solution, the potential of the reference electrode could be calibrated by $E q .1$ taking into consideration the activity coefficient of $\mathrm{Fe}^{2+}$ and $\mathrm{Fe}^{3+}$. As the electrode is home-made, the unoptimized oxidation of $\mathrm{Ag}$ wire (especially considering its small diameter) and the solution exchange between the electrode and the sample may cause non-negligible deviation of its potential. Thus, it is recommended to calibrate the reference electrode potential before use.

Knowing the initial concentration of $\mathrm{Fe}^{3+}$ and $\mathrm{Fe}^{2+}$ in the droplet, with the stoichiometry and the measured potential of the probe, one may derive the concentration of $\mathrm{Fe}^{3+}$ and $\mathrm{Fe}^{2+}$ at any time in the droplet. They can be expressed as follows:

$$
\begin{aligned}
{\left[\mathrm{Fe}^{3+}\right] } & \left.=\frac{\frac{3}{2}\left[\mathrm{Fe}^{3+}\right]_{0}+\left[\mathrm{Fe}^{2+}\right]_{0}}{\frac{3}{2}+\exp \left[\frac{F}{R T}\left(E_{\mathrm{Fe}}^{0 \prime} \mathrm{e}^{3+} / \mathrm{Fe}^{2+}-E_{\text {probe }}\right)\right.}\right] \\
{\left[\mathrm{Fe}^{2+}\right] } & =\frac{\frac{3}{2}\left[\mathrm{Fe}^{3+}\right]_{0}+\left[\mathrm{Fe}^{2+}\right]_{0}}{1+\frac{3}{2} \exp \left[-\frac{F}{R T}\left(\mathrm{Fe}^{0 \prime} e^{3+} / \mathrm{Fe}^{2+}-E_{\text {probe }}\right)\right]} \quad(E q .3)
\end{aligned}
$$

where $\left[\mathrm{Fe}^{3+}\right]_{0}$ and $\left[\mathrm{Fe}^{2+}\right]_{0}$ refer to the initial concentration of $\mathrm{Fe}^{3+}$ and $\mathrm{Fe}^{2+}$ in the droplet, respectively. As a result, the concentration variation as a function of time can be tracked, and it reflects the kinetics of the two reactions R1 and R2, notably the latter which corresponds to the oxidation reactivity of the steel surface.

Fig. 6 shows the variation of the probe potential as a function of time for $20 \mu \mathrm{L}$ droplets on bare steel, silane-coated steel and glass substrates. In all measurements, the potential takes $c a$. $100 \mathrm{~s}$ to stabilize. Afterwards, the potential is almost constant in the droplet on glass substrate, and 
the value is the same as that measured in bulk solution. This suggests that after the response time of the integrated probe, the potentiometric measurements are reliable in small droplets. When the droplet is on bare steel substrate, it is seen that the potential decreases sharply until $c a$. 400 s before reaching a plateau. This can be explained by the oxidization of Fe plate, which consumes $\mathrm{Fe}^{3+}$ in the droplet and generates $\mathrm{Fe}^{2+}$ following the redox reactions $\mathrm{R} 1$ and $\mathrm{R} 2$. For comparison, we also tested the potentiometry of $\mathrm{Fe}^{3+}$ droplet on silane treated $\mathrm{Fe}$ plate. The silane treatment is a known method for temporary protection of metals again corrosion [51-53]. The general trend of the results is the same as on bare Fe plate, but the initial potential decrease is less steep, and the final equilibrium potential is more positive. This suggests that the generation of $\mathrm{Fe}^{2+}$ is slower, on silane-treated $\mathrm{Fe}$ plate than on bare Fe plate, which qualitatively supports the expected corrosion inhibition effect. Nevertheless, this inhibition is less significant (Fig. 6B) with the increase of $\mathrm{Fe}^{3+}$ concentration. This might be related to the stronger attack of the silane film in more harsh media with higher concentration of the oxidant. Similar trends are also seen with other concentration of $\mathrm{Fe}^{3+}$ (Fig. S3). Similar experimental systems have also been used in scanning electrochemical microscopy for analyzing localized corrosion of $\mathrm{Fe}$, where $\mathrm{Fe}$ substrate is locally oxidized to $\mathrm{Fe}^{2+}$ and then $\mathrm{Fe}^{2+}$ is further oxidized to $\mathrm{Fe}^{3+}$ on the microelectrode contributing to the measured current [61].

Potentiometry has an advantage of not perturbing the electrochemical system. Thus, it is especially suitable for in-situ monitoring the variation of concentration of redox species with time, and only very small volume of analyte is required with miniaturized integrated probes. In theory, the results in Fig. 6 make it possible to further quantitatively analyse the kinetics of both reactions R1 and R2. However, in practice, attention must be paid for the experimental control. 
Rigorously, the potential measured from the integrated probe reflects only the surface concentration of $\mathrm{Fe}^{3+}$ and $\mathrm{Fe}^{2+}$ near the probe. Thus, the derivation of Eqs. 2 and 3 from Eq. 1 requires an approximation that the concentration distribution is always uniform in the droplet. When the droplet is static on the surface, this approximation is unlikely fulfilled considering the size of the droplet. Assume the droplet has a contact angle of $60^{\circ}$ with a flat surface, a 20 $\mu \mathrm{L}$ droplet has a height of $c a .0 .156 \mathrm{~cm}$. This will take $c a .76 \mathrm{~s}$ for an analyte generated on the sample surface to reach the top of the droplet (approximately taking linear diffusion with diffusion coefficient $2 \times 10^{-5} \mathrm{~cm}^{2} / \mathrm{s}$ ) where the integrated probe is likely positioned. Another concern is the shape of the droplet, which depends on the contact angle and changes due to the capillary force when in contact with the integrated probe. This complicates the geometry for simulating the electrochemistry with mass transport in the droplet, even with the contact angle measured. Moreover, the response time of the probe is also an issue. From Fig. 4D and Fig. 6, it is clearly seen that the potential takes time to reach equilibrium. This limits the time resolution of the measurement, especially when the potential rapidly changes with time such as between 100 and $300 \mathrm{~s}$ in Fig. 6. Besides, other redox reactions such as R3 and R4 may also interfere the analysis, leading to mixed potential where kinetic effect shall be considered. These reactions may even become dominant when the $\mathrm{Fe}^{3+}$ in the droplet is nearly fully consumed by Fe surface. With all these considerations, the experiments need to be very carefully designed for meaningful quantitative analysis of the kinetics of the interfacial reactions between the droplet and the sample. 
(A)

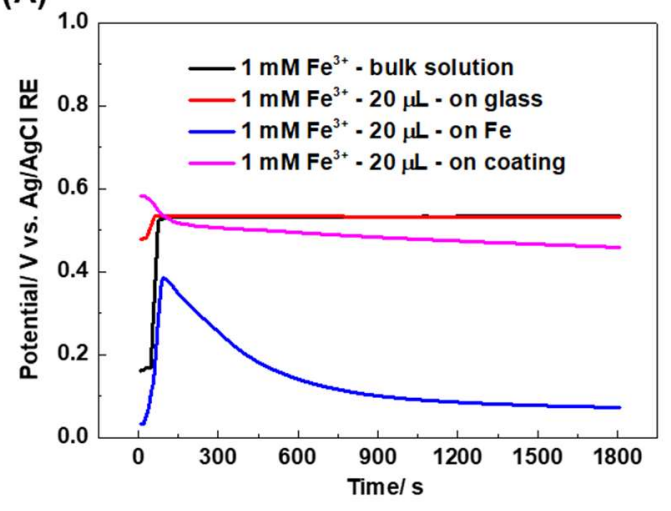

(B)

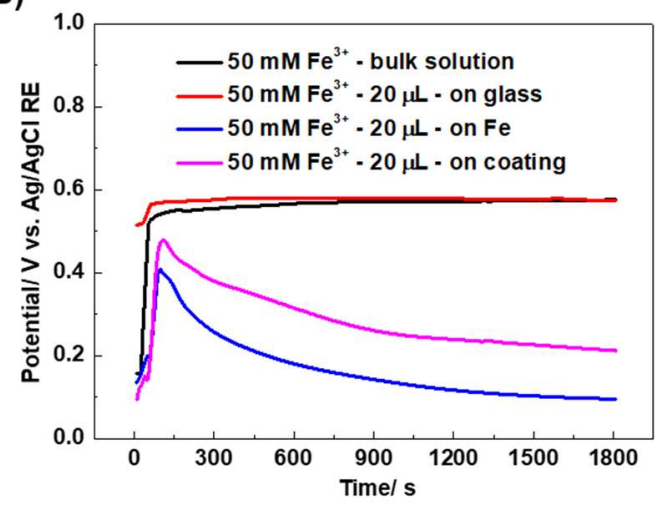

Fig. 6. OCP measurements by integrated probe in $\mathrm{Fe}^{3+}$ bulk solution, $20 \mu \mathrm{L} \mathrm{Fe} \mathrm{F}^{3+}$ droplet on insulating glass, bare and silane-treated $\mathrm{Fe}$ substrates. (A): $1 \mathrm{mM} \mathrm{Fe}^{3+}$, (B): $50 \mathrm{mM} \mathrm{Fe}^{3+}$.

\subsection{Anodic stripping voltammetry in $\mathrm{H}_{2} \mathrm{SO}_{4}$ droplet on $\mathrm{Cu}$ plate}

As shown in Fig. 5, the integrated probe can also be used for voltametric analysis by connecting the $\mathrm{Ag} / \mathrm{AgCl}$ as both $\mathrm{RE}$ and $\mathrm{CE}$. This is further extended to droplet analysis in the form of stripping voltammetry. Stripping voltammetry is a powerful electrochemical measurement for analyzing low concentration of species. With a preconcentration step, the detection limit can reach $\mathrm{nM}$ range $[62,63]$, and it is ideal for electroanalysis of metal ions via electrodeposition followed by anodic stripping [64-67]. The electrode is naturally renewed after stripping, thus it can be used to monitor the change of metal ion concentration in a droplet during the corrosion process [68].

Here, we demonstrate a model system that mimics atmospheric corrosion of $\mathrm{Cu}$ in acidic spray. $20 \mu \mathrm{L}$ of $0.1 \mathrm{M} \mathrm{H}_{2} \mathrm{SO}_{4}$ is dropped on $\mathrm{Cu}$ substrate, and the dissolution of $\mathrm{Cu}$ is followed by anodic stripping analysis of $\mathrm{Cu}^{2+}$ concentration in the droplet using the integrated probe. Fig. 7A shows the anodic stripping signals at different time measured in-situ in the $\mathrm{H}_{2} \mathrm{SO}_{4}$ droplet from the integrated probe. For each measurement, the integrated probe is pre-conditioned at - 
$0.2 \mathrm{~V}(\mathrm{Pt} \mathrm{WE} v s . \mathrm{Ag} / \mathrm{AgCl} \mathrm{RE} / \mathrm{CE}$ ) for $30 \mathrm{~s}$ for pre-concentration in droplets, and then $\mathrm{CV}$ was performed from -0.08 to $0.6 \mathrm{~V}$ ( $\mathrm{Pt} \mathrm{WE} v s$. $\mathrm{Ag} / \mathrm{AgCl} \mathrm{RE} / \mathrm{CE}$ ) for stripping $\mathrm{Cu}$ without moving the probe. It is seen that the area of the stripping peak increases as a function of time, which indicates the corrosion of $\mathrm{Cu}$ in the $\mathrm{H}_{2} \mathrm{SO}_{4}$ droplet. As the charge of $\mathrm{Cu}$ stripping is linear with the concentration of $\mathrm{Cu}^{2+}$ (calibration curve in Fig. 7B), one may derive the variation of $\mathrm{Cu}^{2+}$ concentration in the droplet, as shown in Fig. 7C. It is clearly seen that the signal is low in the first 25 minutes, and afterwards it increases with time. Considering that it takes less than 5 minutes for $\mathrm{Cu}^{2+}$ ions to diffuse from the substrate to the top of the droplet (same estimation as in section 3.4), this phenomenon cannot be only attributed to the lag of detection. According to Mattsson and Bockris [69] and other research workers [70,71], the anodic dissolution of copper takes place through two consecutive steps:

$C u_{s}-e^{-}=C u(I) a d s$ (fast step) (R5)

$\mathrm{Cu}(I)_{a d s}-e^{-}=\mathrm{Cu}(I I)_{\text {sol }}$ (the rate-determining step) (R6)

$\mathrm{R} 5$ refers to an incubation period, where the corrosion yields adsorbed $\mathrm{Cu}(\mathrm{I})$ species that do not dissolve in the solution [72]. This may explain the low concentration of $\mathrm{Cu}^{2+}$ analyzed from the droplet at the initial stage of corrosion. Later, the $\mathrm{Cu}(\mathrm{I})$ species are further oxidized (R6), then $\mathrm{Cu}^{2+}$ concentration increases rapidly, and can be followed by anodic stripping voltammetry. The chemical analysis of the corrosion product in corrosive media is often used for evaluating the corrosion rate, which is a key characteristic for metallic structures. As compared with classical chemical analysis such as ion chromatography $[73,74]$ and inductively coupled plasma atomic emission spectroscopy [75], the integrated probe does not consume the sample and requires only very small volume so that it has merits in in-situ measurements as demonstrated 
in Fig. 2. The corrosion rate is often expressed as weight loss of the metal per time. In the case of $\mathrm{H}_{2} \mathrm{SO}_{4}$ droplet on $\mathrm{Cu}$, the weight loss of $\mathrm{Cu}$ turns into $\mathrm{Cu}^{2+}$ ions in the droplet, thus it can be derived from the following equation:

Corrosion rate $=\frac{V_{\text {droplet }}}{\rho_{C u} A} \cdot \frac{d\left[\mathrm{Cu}^{2+}\right]}{d t} \quad($ Eq. 4)

where $\rho_{C u}$ is the density of $\mathrm{Cu}$ metal, $A$ is the wetted area of the droplet, $V_{\text {droplet }}$ is the volume of the droplet. The corrosion rate is in the unit of thickness per time $(\mu \mathrm{m} / \mathrm{min})$, which can be calculated from the time derivative of Fig. 7C. This simple calculation does not take into account the formation of $\mathrm{Cu}(\mathrm{I})$, but it could still qualitatively reflect the corrosion behavior. The results are shown in Fig. 7D. Note that two different areas (point 1 and point 2 in Fig. 7C and Fig. 7D) of the substrate are tested. The trend of corrosion is similar, but the exact rate is different. This is probably due to the inhomogeneity of the surface, which may sensitively affect the initial stage of corrosion. In another word, it suggests that the integrated probe may offer the possibility to evaluate the local corrosion rate in atmospheric corrosion. 

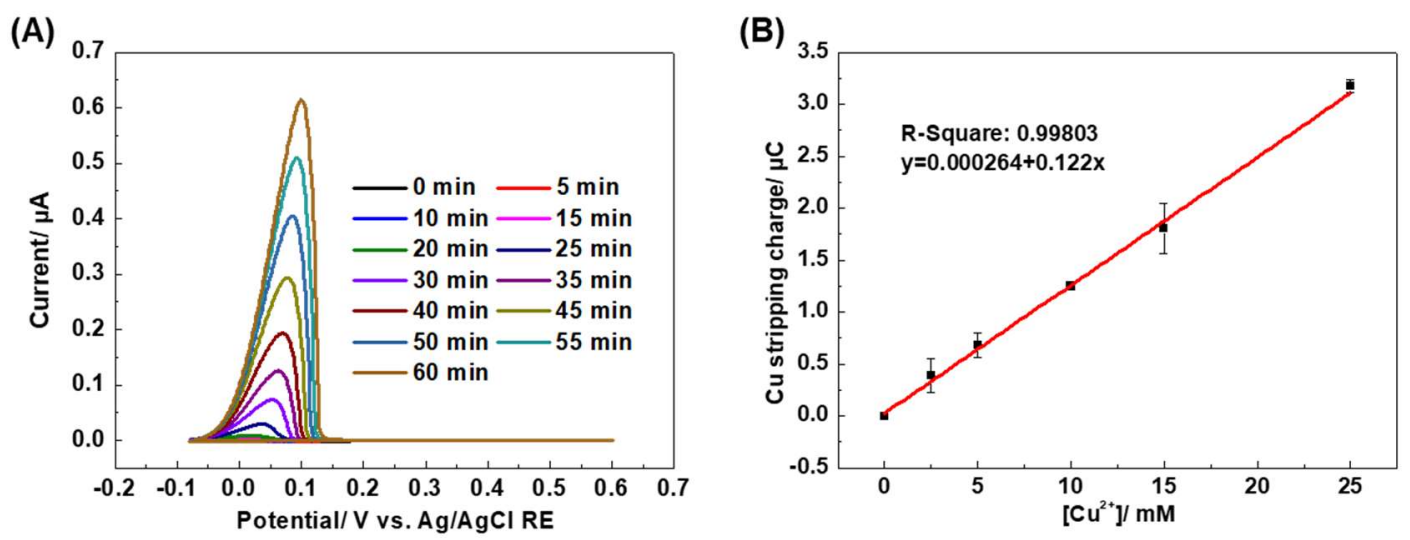

(C)

(D)
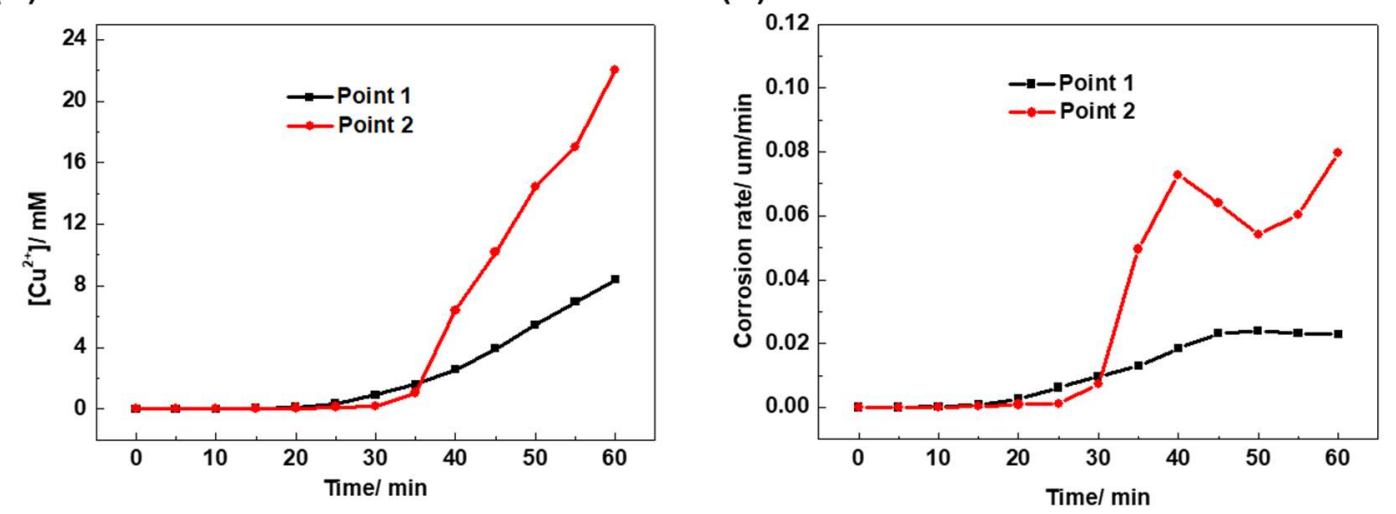

Fig. 7. (A) Anodic stripping signals of $\mathrm{Cu}$ measured in $20 \mu \mathrm{L} 0.1 \mathrm{M} \mathrm{H}_{2} \mathrm{SO}_{4}$ droplet on $\mathrm{Cu}$

plate at different time with interval of $5 \mathrm{~min}$; (B) Calibration curve of $\mathrm{Cu}$ stripping charge $v s$. concentration by the integrated probe in $\mathrm{Cu}^{2+}$ bulk solutions; $(\mathrm{C})\left[\mathrm{Cu}^{2+}\right]$ in the droplet as the function of time; (D) The corrosion rate of $\mathrm{Cu}$ in $\mu \mathrm{m} / \mathrm{min}$, calculated with $\rho_{C u}=8.89 \mathrm{~g} / \mathrm{cm}^{3}$ and $A \approx 0.28 \mathrm{~cm}^{2}$.

\section{Conclusion}

In conclusion, an integrated probe is developed for electrochemical analysis in small volume droplets. The integrated probe consists of a Pt microelectrode, an $\mathrm{Ag} / \mathrm{AgCl}$ wire fixed on the shield of the microelectrode, and an external capillary soaked with electrolyte. With the customized holder, the probe can be easily separated and reassembled, which allows facile and thorough regeneration. The ohmic drop of the gap between the inner microelectrode and the 
outer capillary is acceptable for both potentiometric and voltammetric measurements. The probe is carefully tested and calibrated in bulk solutions, and then is used for in-situ electroanalysis of $20 \mu \mathrm{L}$ droplets. Two systems are tested: (1) potentiometric analysis of $\mathrm{Fe}^{3+}$ droplet on bare and silane-coated Fe; (2) anodic stripping voltammetry of $\mathrm{Cu}^{2+}$ in a $\mathrm{H}_{2} \mathrm{SO}_{4}$ droplet on $\mathrm{Cu}$. In both cases, the results are in good agreement with the corrosion behavior of the substrate, and the corrosion rate can be analyzed. With the improvement of the experimental control, it is also foreseeable to quantitatively derive the kinetics of redox reactions in the droplet or at the droplet/substrate interface. This would be highly helpful for biomedical applications in future, where the analyte is usually in small quantity and quantitative results are expected from in-situ measurements.

\title{
CRediT authorship contribution statement
}

Ning Dang: Investigation, formal analysis, writing-original draft

Nader Djelidi: Investigation

Gustavo Adrián Echeveste Salazar : Investigation

\author{
Alain Walcarius: Supervision
}

Liang Liu: Methodology, funding acquisition, software, writing-review\&editing

Mathieu Etienne: Conceptualisation, methodology, resources

\section{Declaration of Competing Interest}

The authors declare that they have no known competing financial interests or personal relationships that could have appeared to influence the work reported in this paper. 


\section{Acknowledgement}

We gratefully acknowledge financial support from CNRS MOMENTUM Project (2018-2020).

The work is also supported by the Chinese Scholarship Council.

\section{References:}

[1] C.G.J. Schabmueller, D. Loppow, G. Piechotta, B. Schütze, J. Albers, R. Hintsche, Micromachined sensor for lactate monitoring in saliva, Biosens. Bioelectron. 21 (2006) 1770-1776. https://doi.org/10.1016/j.bios.2005.09.015.

[2] P. Wägli, Y.C. Chang, A. Homsy, L. Hvozdara, H.P. Herzig, N.F. De Rooij, Microfluidic droplet-based liquid-liquid extraction and on-chip IR spectroscopy detection of cocaine in human saliva, Anal. Chem. 85 (2013) 7558-7565. https://doi.org/10.1021/ac401606p.

[3] L. Wu, Z. Wang, S. Zong, Y. Cui, Rapid and reproducible analysis of thiocyanate in real human serum and saliva using a droplet SERS-microfluidic chip, Biosens. Bioelectron. 62 (2014) 13-18. https://doi.org/10.1016/j.bios.2014.06.026.

[4] K. Sun, N. Ramgir, S. Bhansali, An immunoelectrochemical sensor for salivary cortisol measurement, Sensors Actuators, B Chem. 133 (2008) 533-537. https://doi.org/10.1016/j.snb.2008.03.018.

[5] X. He, T. Xu, Z. Gu, W. Gao, L.P. Xu, T. Pan, X. Zhang, Flexible and Superwettable Bands as a Platform toward Sweat Sampling and Sensing, Anal. Chem. 91 (2019) 42964300. https://doi.org/10.1021/acs.analchem.8b05875.

[6] H. Yoon, J. Nah, H. Kim, S. Ko, M. Sharifuzzaman, S.C. Barman, X. Xuan, J. Kim, J.Y. 
Park, A chemically modified laser-induced porous graphene based flexible and ultrasensitive electrochemical biosensor for sweat glucose detection, Sensors Actuators, B Chem. 311 (2020) 127866. https://doi.org/10.1016/j.snb.2020.127866.

[7] G. Li, X. Mo, W.C. Law, K.C. Chan, Wearable Fluid Capture Devices for Electrochemical Sensing of Sweat, ACS Appl. Mater. Interfaces. 11 (2019) 238-243. https://doi.org/10.1021/acsami.8b17419.

[8] J.S. Lewis, Z. Barani, A.S. Magana, F. Kargar, Bending, twisting and flapping leaf upon raindrop impact, Bioinspir. Biomim. 15 (2019) 0-31.

[9] F. Viola, Comparison among different rainfall energy harvesting structures, Appl. Sci. 8 (2018). https://doi.org/10.3390/app8060955.

[10] X. Chen, P. Wang, D. Zhang, Designing a Superhydrophobic Surface for Enhanced Atmospheric Corrosion Resistance Based on Coalescence-Induced Droplet Jumping Behavior, ACS Appl. Mater. Interfaces. 11 (2019) 38276-38284. https://doi.org/10.1021/acsami.9b11415.

[11] J. Liao, M. Hotta, Corrosion products of field-exposed Mg-Al series magnesium alloys, Corros. Sci. 112 (2016) 276-288. https://doi.org/10.1016/j.corsci.2016.07.023.

[12] R. Hernandez-Perez, Z.H. Fan, J.L. Garcia-Cordero, Evaporation-Driven Bioassays in Suspended Droplets, Anal. Chem. $88 \quad$ (2016) 7312-7317. https://doi.org/10.1021/acs.analchem.6b01657.

[13] A.M. Seddon, S.J. Richardson, K. Rastogi, T.S. Plivelic, A.M. Squires, C. Pfrang, Control of Nanomaterial Self-Assembly in Ultrasonically Levitated Droplets, J. Phys. Chem. Lett. 7 (2016) 1341-1345. https://doi.org/10.1021/acs.jpclett.6b00449. 
[14] T. Wang, J. Lin, X. Guo, Y. Lei, H. Fu, A new method for producing uniform droplets by continuous-ink-jet technology, Rev. Sci. Instrum. 89 (2018). https://doi.org/10.1063/1.5041503.

[15] H.Y.Y. Nyein, L.C. Tai, Q.P. Ngo, M. Chao, G.B. Zhang, W. Gao, M. Bariya, J. Bullock, H. Kim, H.M. Fahad, A. Javey, A Wearable Microfluidic Sensing Patch for Dynamic Sweat Secretion Analysis, ACS Sensors. 3 (2018) 944-952. https://doi.org/10.1021/acssensors.7b00961.

[16] J. Choi, A.J. Bandodkar, J.T. Reeder, T.R. Ray, A. Turnquist, S.B. Kim, N. Nyberg, A. Hourlier-Fargette, J.B. Model, A.J. Aranyosi, S. Xu, R. Ghaffari, J.A. Rogers, Soft, skinintegrated multifunctional microfluidic systems for accurate colorimetric analysis of sweat biomarkers and temperature, ACS Sensors. 4 (2019) 379-388. https://doi.org/10.1021/acssensors.8b01218.

[17] R. Yang, H. Hou, Y. Wang, L. Fu, Micro-magnetofluidics in microfluidic systems : A review, Sens. Actuators B Chem. 224 (2016) 1-15. http://dx.doi.org/10.1016/j.snb.2015.10.053.

[18] M. Boyd-Moss, S. Baratchi, M. Di Venere, K. Khoshmanesh, Self-contained microfluidic systems: A review, Lab Chip. 16 (2016) 3177-3192. https://doi.org/10.1039/c6lc00712k.

[19] Z. Taleat, A. Khoshroo, M. Mazloum-Ardakani, Screen-printed electrodes for biosensing: A review (2008-2013), Microchim. Acta. 181 (2014) 865-891. https://doi.org/10.1007/s00604-014-1181-1.

[20] M. Li, Y.T. Li, D.W. Li, Y.T. Long, Recent developments and applications of screen- 
printed electrodes in environmental assays-A review, Anal. Chim. Acta. 734 (2012) 3144. https://doi.org/10.1016/j.aca.2012.05.018.

[21] D. Li, C. Batchelor-Mcauley, L. Chen, R.G. Compton, Band Electrodes in Sensing Applications: Response Characteristics and Band Fabrication Methods, ACS Sensors. 4 (2019) 2250-2266. https://doi.org/10.1021/acssensors.9b01172.

[22] L. Challier, R. Miranda-Castro, D. Marchal, V. Noël, F. Mavré, B. Limoges, Kinetic rotating droplet electrochemistry: A simple and versatile method for reaction progress kinetic analysis in microliter volumes, J. Am. Chem. Soc. 135 (2013) 14215-14228. https://doi.org/10.1021/ja405415q.

[23] C. Kranz, Recent advancements in nanoelectrodes and nanopipettes used in combined scanning electrochemical microscopy techniques, Analyst. 139 (2013) 336-352. https://doi.org/10.1039/c3an01651j.

[24] J.E. Dick, C. Renault, B.K. Kim, A.J. Bard, Simultaneous detection of single attoliter droplet collisions by electrochemical and electrogenerated chemiluminescent responses, Angew. Chemie Int. Ed. 53 (2014) 11859-11862. https://doi.org/10.1002/anie.201407937.

[25] M. Donten, Z. Stojek, F. Scholz, Electron transfer - Ion insertion electrochemistry at an immobilised droplet: Probing the three-phase electrode-reaction zone with a Pt disk microelectrode, Electrochem. Commun. 4 (2002) 324-329. https://doi.org/10.1016/S1388-2481(02)00302-8.

[26] M.M. Lohrengel, Electrochemical capillary cells, Corros. Eng. Sci. Technol. 39 (2004) 53-58. https://doi.org/10.1179/147842204225016877. 
[27] D. Filotás, B.M. Fernández-Pérez, A. Kiss, L. Nagy, G. Nagy, R.M. Souto, Double barrel microelectrode assembly to prevent electrical field effects in potentiometric SECM imaging of galvanic corrosion processes, J. Electrochem. Soc. 165 (2018) C270-C277. https://doi.org/10.1149/2.0671805jes.

[28] N. Ebejer, A.G. Güell, S.C.S. Lai, K. McKelvey, M.E. Snowden, P.R. Unwin, Scanning Electrochemical Cell Microscopy: A Versatile Technique for Nanoscale Electrochemistry and Functional Imaging, Annu. Rev. Anal. Chem. 6 (2013) 329-351. https://doi.org/10.1146/annurev-anchem-062012-092650.

[29] C.L. Bentley, M. Kang, P.R. Unwin, Scanning electrochemical cell microscopy: New perspectives on electrode processes in action, Curr. Opin. Electrochem. 6 (2017) 23-30. https://doi.org/10.1016/j.coelec.2017.06.011.

[30] E. Daviddi, Z. Chen, B. Beam Massani, J. Lee, C.L. Bentley, P.R. Unwin, E.L. Ratcliff, Nanoscale Visualization and Multiscale Electrochemical Analysis of Conductive Polymer Electrodes, ACS Nano. (2019). https://doi.org/10.1021/acsnano.9b06302.

[31] C.L. Bentley, M. Kang, P.R. Unwin, Nanoscale Structure Dynamics within Electrocatalytic Materials, J. Am. Chem. Soc. 139 (2017) 16813-16821. https://doi.org/10.1021/jacs.7b09355.

[32] J. Ustarroz, I.M. Ornelas, G. Zhang, D. Perry, M. Kang, C.L. Bentley, M. Walker, P.R. Unwin, Mobility and Poisoning of Mass-Selected Platinum Nanoclusters during the Oxygen Reduction Reaction, ACS Catal. 8 (2018) 6775-6790. https://doi.org/10.1021/acscatal.8b00553.

[33] C.L. Bentley, M. Kang, F.M. Maddar, F. Li, M. Walker, J. Zhang, P.R. Unwin, 
Electrochemical maps and movies of the hydrogen evolution reaction on natural crystals of molybdenite $\left(\mathrm{MoS}_{2}\right)$ : Basal: vs. edge plane activity, Chem. Sci. 8 (2017) 6583-6593. https://doi.org/10.1039/c7sc02545a.

[34] J.C. Byers, A.G. Güell, P.R. Unwin, Nanoscale electrocatalysis: Visualizing oxygen reduction at pristine, kinked, and oxidized sites on individual carbon nanotubes, J. Am. Chem. Soc. 136 (2014) 11252-11255. https://doi.org/10.1021/ja505708y.

[35] T. Tarnev, H.B. Aiyappa, A. Botz, T. Erichsen, A. Ernst, C. Andronescu, W. Schuhmann, Scanning Electrochemical Cell Microscopy Investigation of Single ZIF-Derived Nanocomposite Particles as Electrocatalysts for Oxygen Evolution in Alkaline Media, Angew. Chemie Int. Ed. $58 \quad$ (2019) 14265-14269. https://doi.org/10.1002/anie.201908021.

[36] A. Kumatani, C. Miura, H. Kuramochi, T. Ohto, M. Wakisaka, Y. Nagata, H. Ida, Y. Takahashi, K. Hu, S. Jeong, J. ichi Fujita, T. Matsue, Y. Ito, Chemical Dopants on Edge of Holey Graphene Accelerate Electrochemical Hydrogen Evolution Reaction, Adv. Sci. 6 (2019). https://doi.org/10.1002/advs.201900119.

[37] C.L. Bentley, M. Kang, P.R. Unwin, Nanoscale Surface Structure-Activity in Electrochemistry and Electrocatalysis, J. Am. Chem. Soc. (2018). https://doi.org/10.1021/jacs.8b09828.

[38] R.G. Mariano, K. McKelvey, H.S. White, M.W. Kanan, Selective increase in $\mathrm{CO}_{2}$ electroreduction activity at grain-boundary surface terminations, Science 358 (2017) 1187-1192. https://doi.org/10.1126/science.aao3691.

[39] Y. Takahashi, Y. Kobayashi, Z. Wang, Y. Ito, M. Ota, H. Ida, A. Kumatani, K. Miyazawa, 
T. Fujita, H. Shiku, Y.E. Korchev, Y. Miyata, T. Fukuma, M. Chen, T. Matsue, HighResolution Electrochemical Mapping of the Hydrogen Evolution Reaction on Transition-Metal Dichalcogenide Nanosheets, Angew. Chemie Int. Ed. 59 (2020) 36013608. https://doi.org/10.1002/anie.201912863.

[40] C.L. Bentley, C. Andronescu, M. Smialkowski, M. Kang, T. Tarnev, B. Marler, P.R. Unwin, U.P. Apfel, W. Schuhmann, Local Surface Structure and Composition Control the Hydrogen Evolution Reaction on Iron Nickel Sulfides, Angew. Chemie Int. Ed. 57 (2018) 4093-4097. https://doi.org/10.1002/anie.201712679.

[41] D.Q. Liu, B. Tao, H.C. Ruan, C.L. Bentley, P.R. Unwin, Metal support effects in electrocatalysis at hexagonal boron nitride, Chem. Commun. 55 (2019) 628-631. https://doi.org/10.1039/c8cc08517j.

[42] E. Daviddi, K.L. Gonos, A.W. Colburn, C.L. Bentley, P.R. Unwin, Scanning Electrochemical Cell Microscopy (SECCM) Chronopotentiometry: Development and Applications in Electroanalysis and Electrocatalysis, Anal. Chem. 91 (2019) 9229-9237. https://doi.org/10.1021/acs.analchem.9b02091.

[43] P.E. Sharel, M. Kang, P. Wilson, L. Meng, D. Perry, A. Basile, P.R. Unwin, High resolution visualization of the redox activity of $\mathrm{Li}_{2} \mathrm{O}_{2}$ in non-aqueous media: Conformal layer: Vs. toroid structure, Chem. Commun. 54 (2018) 3053-3056. https://doi.org/10.1039/c7cc09957f.

[44] Y. Takahashi, A. Kumatani, H. Munakata, H. Inomata, K. Ito, K. Ino, H. Shiku, P.R. Unwin, Y.E. Korchev, K. Kanamura, T. Matsue, Nanoscale visualization of redox activity at lithium-ion battery cathodes, Nat. Commun. 5 (2014) 1-7. 
https://doi.org/10.1038/ncomms6450.

[45] M. Dayeh, M.R.Z. Ghavidel, J. Mauzeroll, S.B. Schougaard, Micropipette Contact Method to Investigate High-Energy Cathode Materials by using an Ionic Liquid, ChemElectroChem. 6 (2019) 195-201. https://doi.org/10.1002/celc.201800750.

[46] B. Tao, L.C. Yule, E. Daviddi, C.L. Bentley, P.R. Unwin, Correlative Electrochemical Microscopy of Li-Ion (De)intercalation at a Series of Individual $\mathrm{LiMn}_{2} \mathrm{O}_{4}$ Particles , Angew. Chemie. 131 (2019) 4654-4659. https://doi.org/10.1002/ange.201814505.

[47] V. Shkirskiy, L.C. Yule, E. Daviddi, C.L. Bentley, J. Aarons, G. West, Nanoscale scanning electrochemical cell microscopy and correlative surface structural analysis to map anodic and cathodic reactions on polycrystalline $\mathrm{Zn}$ in acid media, J. Electrochem. Soc. 167 (2020). https://doi.org/10.1149/1945-7111/ab739d.

[48] L.C. Yule, C.L. Bentley, G. West, B.A. Shollock, P.R. Unwin, Scanning electrochemical cell microscopy: A versatile method for highly localised corrosion related measurements on metal surfaces, Electrochim. Acta. $298 \quad$ (2019) 80-88. https://doi.org/10.1016/j.electacta.2018.12.054.

[49] L.C. Yule, V. Shkirskiy, J. Aarons, G. West, C.L. Bentley, B.A. Shollock, P.R. Unwin, Nanoscale Active Sites for the Hydrogen Evolution Reaction on Low Carbon Steel, J. Phys. Chem. C. 123 (2019) 24146-24155. https://doi.org/10.1021/acs.jpcc.9b07216.

[50] B. Ramírez Barat, E. Cano, In-situ EIS measurements and their interpretation for the diagnostic of metallic cultural heritage: a review, ChemElectroChem. 15 (2018) 26982716. https://doi.org/https://doi.org/10.1002/celc.201800844.

[51] L. Liu, J.M. Hu, J.Q. Zhang, C.N. Cao, Improving the formation and protective 
properties of silane films by the combined use of electrodeposition and nanoparticles incorporation, Electrochim. Acta. $52 \quad$ (2006) 538-545. https://doi.org/10.1016/j.electacta.2006.05.034.

[52] J.M. Hu, L. Liu, J.Q. Zhang, C.N. Cao, Electrodeposition of silane films on aluminum alloys for corrosion protection, Prog. Org. Coatings. 58 (2007) 265-271. https://doi.org/10.1016/j.porgcoat.2006.11.008.

[53] L. Liu, J.M. Hu, J.Q. Zhang, C.N. Cao, Comment on electrodeposited silicate films: Importance of supporting electrolyte, Anal. Chem. 81 (2009) 3199-3200. https://doi.org/10.1021/ac900184h.

[54] S.M. Sibug-Torres, L.P. Go, E.P. Enriquez, Fabrication of a 3d-printed porous junction for $\mathrm{Ag}|\mathrm{AgCl}| \mathrm{gel}-\mathrm{KCl}$ reference electrode, Chemosensors. $8 \quad$ (2020) 1-20. https://doi.org/10.3390/chemosensors8040130.

[55] M. Etienne, J.P. Moulin, S. Gourhand, Accurate control of the electrode shape for high resolution shearforce regulated SECM, Electrochim. Acta. 110 (2013) 16-21. https://doi.org/10.1016/j.electacta.2013.03.096.

[56] M.S. Mika Sillanpää, Electrochemcial Water Treatment Methods: fundamentals, methods and full scale applications, Butterworth-Heinemann, 2017.

[57] B.Y. Chang, S.M. Park, Electrochemical impedance spectroscopy of composite adhesive joints, Annu. Rev. Anal. Chem. (Palo Alto. Calif). 3 (2010) 207-229. https://doi.org/10.1146/annurev.anchem.012809.102211.

[58] A. Lasia, Modern Aspects of Electrochemistry, Kluwer Academic Publishers, New York, Boston, Dordrecht, London, Moscow, 2017. 
[59] A.J. Bard, L.R. Faulkner, Fundamentals and applications: electrochemical methods., Wiley, New York, 2001.

[60] I. Turyan, N. Khatwani, Z. Sosic, S. Jayawickreme, D. Mandler, A novel approach for oxidation analysis of therapeutic proteins, Anal. Biochem. 494 (2016) 108-113. https://doi.org/10.1016/j.ab.2015.10.015.

[61] A.M. Simões, A.C. Bastos, M.G. Ferreira, Y. González-García, S. González, R.M. Souto, Use of SVET and SECM to study the galvanic corrosion of an iron-zinc cell, Corros. Sci. 49 (2007) 726-739. https://doi.org/10.1016/j.corsci.2006.04.021.

[62] C.A. Rusinek, A. Bange, I. Papautsky, W.R. Heineman, Cloud Point Extraction for Electroanalysis: Anodic Stripping Voltammetry of Cadmium, Anal. Chem. 87 (2015) 6133-6140. https://doi.org/10.1021/acs.analchem.5b00701.

[63] K.Z. Brainina, N.A. Malakhova, N.Y. Stojko, Stripping voltammetry in environmental and food analysis, Fresenius. J. Anal. Chem. 368 (2000) 307-325. https://doi.org/10.1007/s002160000525.

[64] I.M. Svishchev, R.A. Carvajal-Ortiz, K.I. Choudhry, D.A. Guzonas, Corrosion behavior of stainless steel 316 in sub- and supercritical aqueous environments: Effect of $\mathrm{LiOH}$ additions, Corros. Sci. 72 (2013) 20-25. https://doi.org/10.1016/j.corsci.2013.02.005.

[65] M. Solakidou, A. Giannakas, Y. Georgiou, N. Boukos, M. Louloudi, Y. Deligiannakis, Efficient photocatalytic water-splitting performance by ternary $\mathrm{CdS} / \mathrm{Pt}-\mathrm{N}-\mathrm{TiO}_{2}$ and $\mathrm{CdS} / \mathrm{Pt}-\mathrm{N}, \mathrm{F}-\mathrm{TiO}_{2}$ : Interplay between $\mathrm{CdS}$ photo corrosion and $\mathrm{TiO}_{2}$-dopping, Appl. Catal. B Environ. 254 (2019) 194-205. https://doi.org/10.1016/j.apcatb.2019.04.091.

[66] M. Nie, S. Neodo, J.A. Wharton, A. Cranny, N.R. Harris, R.J.K. Wood, K.R. Stokes, 
Electrochemical detection of cupric ions with boron-doped diamond electrode for marine corrosion monitoring, Electrochim. Acta. 202 (2016) 345-356. https://doi.org/10.1016/j.electacta.2015.12.194.

[67] A. Cranny, N.R. Harris, M. Nie, J.A. Wharton, R.J.K. Wood, K.R. Stokes, Sensors for corrosion detection: Measurement of copper ions in 3.5\% sodium chloride using screenprinted platinum electrodes, IEEE Sens. J. 12 (2012) 2091-2099. https://doi.org/10.1109/JSEN.2012.2183867.

[68] A. López-Delgado, A Laboratory Study of the Effect of Acetic Acid Vapor on Atmospheric Copper Corrosion, J. Electrochem. Soc. $145 \quad$ (1998) 4140. https://doi.org/10.1149/1.1838928.

[69] E. Matisson, J.O.M. Bockris, Galvanostatic studies of the kinetics of deposition and dissolution in the copper + copper sulphate system, Trans. Faraday Soc. 55 (1959) 15861601. https://doi.org/10.1039/tf9595501586.

[70] A.W.C. Ller, Mechanism of Copper in Acidic Sulfate Solutions, Electrochim. Acta. 38 (1993) 2121-2127.

[71] G.G.O. Cordeiro, O.E. Barcia, O.R. Mattos, Copper electrodissolution mechanism in a 1M sulphate medium, Electrochim. Acta. $38 \quad$ (1993) 319-324. https://doi.org/10.1016/0013-4686(93)85146-P.

[72] M. Khodari, M.M. Abou-Krisha, F.H. Assaf, F.M. El-Cheikh, A.A. Hussien, Stripping voltammetric and conductance measurements on corrosion and inhibition of copper in nitric acid, Mater. Chem. Phys. 71 (2001) 279-290. https://doi.org/10.1016/S02540584(01)00291-7. 
[73] M. Jönsson, D. Persson, D. Thierry, Corrosion product formation during $\mathrm{NaCl}$ induced atmospheric corrosion of magnesium alloy AZ91D, Corros. Sci. 49 (2007) 1540-1558. https://doi.org/10.1016/j.corsci.2006.08.004.

[74] D.Z. Živojinović, L. V. Rajaković, Application and validation of ion chromatography for the analysis of power plants water: Analysis of corrosive anions in conditioned water-steam cycles, Desalination. $275 \quad$ (2011) 17-25. https://doi.org/10.1016/j.desal.2011.02.058.

[75] R. Carlini, M.M. Carnasciali, F. Soggia, S. Campodonico, G. Zanicchi, ICP-AES and MicroRaman corrosion behaviour investigation on $\mathrm{Zn}_{4} \mathrm{Sb}_{3}$ and $\mathrm{Al}$, $\mathrm{Ag}$ doped phases in sodium chloride solution, J. Alloys Compd. 588 (2014) 361-365. https://doi.org/10.1016/j.jallcom.2013.11.059. 